\title{
Optimization of Flavored Toned Milk from Carabao (Bubalus bubalis carabanesis)
}

\author{
Kennlourd Faoust Villo ${ }^{1 \star}$, Roberta D. Lauzon ${ }^{2}$, Felix Amestoso ${ }^{3}$, and \\ Nilda Amestoso ${ }^{4}$
}

\section{ABSTRACT}

The study aimed to optimize the formulation of flavored toned milk beverage using Response Surface Methodology (RSM). A 7-variable 8-run Plackett-Burman (PB) design and a $3^{3}$ fractional factorial experiment following Central Composite Design (CCD) were used for the variable screening experiment and the optimization study, respectively. Sensory attributes like color, aroma, mouthfeel, taste, sweetness, and general acceptability were the response parameters considered. Variable screening revealed that sugar, mango, and vanilla flavors were the three factors that significantly affected the sensory attributes of the product. These selected variables were then used in the optimization study. The levels of the independent variables significantly affected the color, sweetness, and general acceptability of the product. The levels satisfying the optimum region were: $\mathrm{p}<0.05 .0-14.8 \% \mathrm{w} / \mathrm{v}$ sugar, $0-0.8 \% \mathrm{w} / \mathrm{v}$ mango, and $0-0.4 \% \mathrm{w} / \mathrm{v}$ vanilla. The sugar level of $13.6 \%(\mathrm{w} / \mathrm{v})$, vanilla level of $0.12 \%(\mathrm{w} / \mathrm{v})$, and $0 \%$ $(\mathrm{w} / \mathrm{v})$ mango level was verified as the optimum combination for flavored toned milk. Results revealed that among the responses, only the values of the actual and predicted aroma acceptability of the product were not significantly different. This implies that the proposed model equation was only fit for predicting the aroma acceptability of the product. Observed acceptability had a higher rating than the predicted value, indicating that the panelists may have improved their evaluation with less confusion when there were only two samples presented. The optimum formulation of flavored toned milk and the commercial chocolate milk were subjected to consumer evaluation to assess the acceptability of the beverage and to evaluate the preference of consumers between the newly developed and the existing milk product in the local market. The optimum formulation was accepted among $88 \%$ of the respondents while $90 \%$ liked the commercial sample. Chi-square test results showed no significant difference between

\footnotetext{
${ }^{1}$ Kauswagan Mahayahay Bankal Lapu-Lapu City, Cebu, Philippines

${ }^{2}$ Visayas State University, Department of Food Science and Technology, Visca, Baybay City, Leyte, Philippines
} 


\section{Optimization of Flavored Toned Milk from Carabao}

the two. This implies that the optimum formulation can compete with the existing commercial product in terms of sensory acceptability. A liter of commercial milk costs Php 80 while the optimum formulation (sugar level of $13.6 \% \mathrm{w} / \mathrm{v}$, vanilla level of $0.12 \% \mathrm{w} / \mathrm{v}$, and mango level of $0 \% \mathrm{w} / \mathrm{v}$ ) only costs Php 76 per liter.

Keywords: flavored toned milk, optimization, sensory, variable screening

\section{INTRODUCTION}

Good nutrition and access to an adequate diet are essential for child growth and development, body maintenance, and protection from both infectious and non-communicable diseases in adult life. Adequate nutrition and a healthy productive population are increasingly recognized as important prerequisites for poverty reduction and economic and social development. Improvements in family diets and children's nutritional status globally are thus imperative for achieving the Millennium Development Goals (MDGs) related to the eradication of extreme poverty and hunger and increasing child survival (Food and Agriculture Organization [FAO] 2017).

Too many Filipinos suffer from one or more forms of malnutrition caused by various reasons like poverty, population increase, politics, pathology, and production and preservation of food from wastage and loss (Kreiß। 2009). The four major deficiency disorders among Filipino children are protein-energy malnutrition (PEM), Vitamin A Deficiency (VAD), Iron Deficiency Anemia (IDA), and lodine Deficiency Disorder (IDD). High fatality rates among infants and children are caused by PEM, expecially by kwashiorkor, marasmus or marasmic kwashiorkor.

Daily milk intake helps fight malnutrition and other deficiency disorders. This is because milk is considered a complete food. However, the high cost of milk makes the product unaffordable especially among low income people who are often the victims of malnutrition. The high cost of milk and milk-based products can be due to the fact that the Philippines is not a dairy producing country. At present, about $98 \%$ of the country's milk supply is imported from milk producing countries. Because of this, the country is spending its hard-earned dollar to procure milk annually, making milk the 4th top agricultural import.

One of the sources of milk consumed by Filipinos is buffalo. Buffalo milk is better compared with the milk of other animals because of its high fat and protein content. These characteristics make buffalo's milk ideal for the development of toned milk.

Toned milk is ideal for nutrient supplementation. It is relatively cheaper but its nutritive quality is comparable to fresh milk. Although milk toning affects the flavor of the milk due to water dilution, which makes it bland, the 
incorporation of flavorants will answer this problem. One popular commercial toned milk is choco-flavored toned milk. Aside from chocolate, there are other natural flavorants like fruits and natural plant extracts like vanilla, which are worth investigating. Hence, the study was conducted to optimize and evaluate the quality and acceptability of flavored toned milk from buffalo.

Toned milk is done by adding water to whole buffalo milk to reduce fat content. This is 'toned up' by adding skim milk powder to increase Solid-nonFat (SNF) content. Milk properties vary according to animal source, season, and milk storage conditions. This may imply that processes have to adapt to the variation in properties. Based on 'Definitions and standards as per Food Safety and Standards Authority of India (FSSAI) Regulation', toned milk should have at least 3\% fat and $8.5 \%$ Solid-non-Fat and unadulterated buffalo milk should have at least $6 \%$ fat and $9 \%$ Solid-non-Fat. Thus, dilution of fat in unadulterated buffalo milk by the addition of water, to double its volume, should produce milk containing at least $3 \%$ fat and $4.5 \%$ Solid-nonFat. The addition of at least $4 \%$ skim milk would 'tone up' milk to meet the FSSAI regulation for toned milk.

It is important to consider the products' nutritional benefits and acceptability to consumers, hence the need for optimizing all aspects of production in an effective way to successfully develop a new product. Therefore, the focus of the present investigation is to optimize the formulation and processing of flavored toned milk to improve consumer acceptability by using Response Surface Methodology (RSM).

\section{MATERIALS AND METHODS}

\section{Procurement of Materials}

Pasteurized carabao milk was purchased from the Philippine Carabao Center (PCC) at the Visayas State University. All other ingredients were purchased at Baybay City, Leyte.

\section{Preliminary Experiment}

The Plackett-Burman experimental design was used to screen the most important factors that influenced the production of flavored toned milk. The seven input variables for 8 runs included: sugar level, skim milk powder level, temperature upon serving, taro (BSLM 115), cooking time, vanilla extract level, and mango level (Tables $1 \& 2$ ). Each variable had two levels: high level (+) and low level (-), to be examined. Sensory evaluation was conducted on the eight runs considering the color, aroma, mouthfeel, taste, sweetness, and general acceptability of the product. 
Optimization of Flavored Toned Milk from Carabao

Table 1. High and low values for screening experiment of flavored toned milk

\begin{tabular}{lll}
\hline \multicolumn{1}{c}{ Variables } & \multicolumn{2}{c}{ Range } \\
\cline { 2 - 3 } & \multicolumn{1}{c}{ LOW } & HIGH \\
\hline 1. Sugar level & $2 \% \mathrm{w} / \mathrm{v}$ & $10 \% \mathrm{w} / \mathrm{v}$ \\
2. Skim milk powder level & $4 \% \mathrm{w} / \mathrm{v}$ & $6 \% \mathrm{w} / \mathrm{v}$ \\
3. Temp. upon serving & Chilled $\left(5{ }^{\circ} \mathrm{C}\right)$ & Room temp. $\left(23^{\circ} \mathrm{C}\right)$ \\
4. Taro (BSLM 115) & $0.1 \% \mathrm{w} / \mathrm{v}$ & $0.5 \% \mathrm{w} / \mathrm{v}$ \\
5. Cooking Time & $10 \mathrm{mins}$. & $15 \mathrm{mins}$. \\
6. Vanilla extract level & $0.1 \% \mathrm{w} / \mathrm{v}$ & $0.5 \% \mathrm{w} / \mathrm{v}$ \\
7. Mango level & $2 \% \mathrm{w} / \mathrm{v}$ & $3 \% \mathrm{w} / \mathrm{v}$ \\
\hline
\end{tabular}

Table 2. A 7 variable - 8 run Plackett-Burman design of experiment for flavored toned milk

\begin{tabular}{cccccccc}
\hline Run & $\begin{array}{c}\text { Sugar } \\
(\% \mathbf{w} / \mathbf{v})\end{array}$ & $\begin{array}{c}\text { Skim Milk } \\
\text { Powder } \\
(\% \mathbf{w})\end{array}$ & $\begin{array}{c}\text { Temp. upon } \\
\text { Serving } \\
\left({ }^{\circ} \mathbf{C}\right)\end{array}$ & $\begin{array}{c}\text { Taro BSLM } \\
(\% \mathbf{w} / \mathbf{v})\end{array}$ & $\begin{array}{c}\text { Cooking } \\
\text { Time } \\
(\mathbf{m i n})\end{array}$ & $\begin{array}{c}\text { Vanilla } \\
(\% \mathbf{w} / \mathbf{v})\end{array}$ & $\begin{array}{c}\text { Mango } \\
(\% w / v)\end{array}$ \\
\hline 1 & 10 & 6 & 23 & 0.1 & 15 & 0.1 & 2 \\
2 & 10 & 6 & 5 & 0.5 & 10 & 0.1 & 3 \\
3 & 10 & 4 & 23 & 0.1 & 10 & 0.5 & 3 \\
4 & 2 & 6 & 5 & 0.1 & 15 & 0.5 & 3 \\
5 & 10 & 4 & 5 & 0.5 & 15 & 0.5 & 2 \\
6 & 2 & 4 & 23 & 0.5 & 15 & 0.1 & 3 \\
7 & 2 & 6 & 23 & 0.5 & 10 & 0.5 & 2 \\
8 & 2 & 4 & 5 & 0.1 & 10 & 0.1 & 2 \\
\hline
\end{tabular}

\section{Experimental Design for Optimization Experiment}

After the variable screening experiments, the most significant variables chosen were optimized. In order to determine the optimum conditions and formulations, a $3^{3}$ fractional factorial experiment was used following the Central Composite Design (CCD) of Experiment with 15 treatments (Figure 1) for experimental combinations. The three variables that gave the most significant effect were identified.

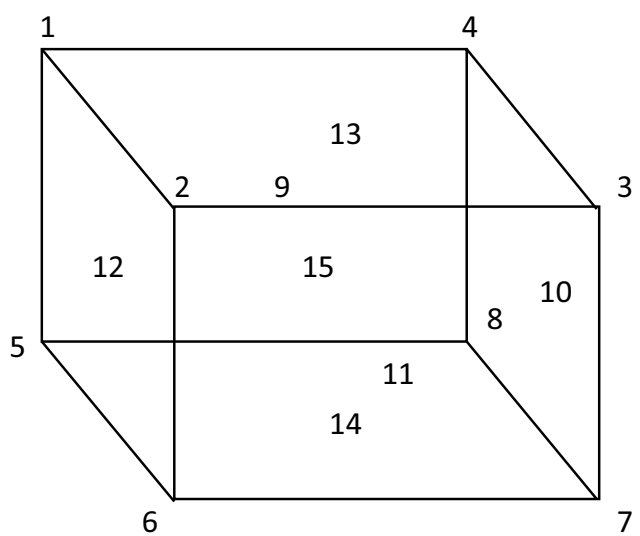

Figure 1. A Central Composite Design (CCD) for flavored toned milk optimization 


\section{Preparation and Processing of Flavored Toned Milk}

Pasteurized carabao's milk was diluted in equal amount of water per volume. Skim milk powder ( $4 \% \mathrm{w} / \mathrm{v})$, sugar $(5 \%, 10 \%, 15 \% \mathrm{w} / \mathrm{v})$, synthetic mango flavor $(5 \%, 10 \%, 15 \% \mathrm{w} / \mathrm{v})$, and vanilla extract $(0 \%, 0.2 \%, 0.4 \% \mathrm{w} / \mathrm{v})$ were added based on the solution and pasteurized at $80^{\circ} \mathrm{C}$ for 10 to 15 minutes. It was then cooled to $23^{\circ} \mathrm{C}$ and packed in a PET bottle. Storage was at $5^{\circ} \mathrm{C}$ (Figure 2 ).

\section{Sensory Evaluation}

Sensory evaluation for variable screening was conducted using the seven input variables for 8 runs namely: sugar level ( $2 \% \mathrm{w} / \mathrm{v}, 10 \% \mathrm{w} / \mathrm{v})$, skim milk powder level $(4 \% \mathrm{w} / \mathrm{v}, 6 \% \mathrm{w} / \mathrm{v})$, temperature upon serving $\left(5^{\circ} \mathrm{C}, 23^{\circ} \mathrm{C}\right)$, taro $(0.1 \% \mathrm{w} / \mathrm{v}, 0.5 \% \mathrm{w} / \mathrm{v})$, cooking time $(10,15 \mathrm{mins}$.), vanilla extract level $(0.1 \% \mathrm{w} / \mathrm{v}, 0.5 \% \mathrm{w} / \mathrm{v})$, and mango( $2 \% \mathrm{w} / \mathrm{v}, 3 \% \mathrm{w} / \mathrm{v})$.

The most significant variables were used to determine optimum conditions and formulations using a $3^{3}$ fractional factorial experiment, following the Central Composite Design (CCD) of Experiment with 15 treatments.

The different formulations were subjected to sensory evaluation for color, aroma, mouth feel, taste, sweetness, and general acceptability by 75 panelists composed of VSU students and staff of the Department of Food Science and Technology. Table for set plan 13.7 ( $t=5, k=7, r=7, b=15, \lambda=3$, $\mathrm{E}=0.92$, Type I) of Incomplete Block Design (IBD) was used for the sensory evaluation (Cochran \& Cox 1957).

\section{Statistical Analysis}

Sensory evaluation results were analyzed by Response Surface Regression (RSREG) analysis using Statistica Software version 9 to determine the effects of the independent variables on the sensory attributes of the product and the optimum processing conditions for each independent variable for the response studied. Effects of the independent variables were simplified by contour plots and the optimum conditions defined for processing the product using the highest possible product acceptability common to all sensory qualities evaluated. 


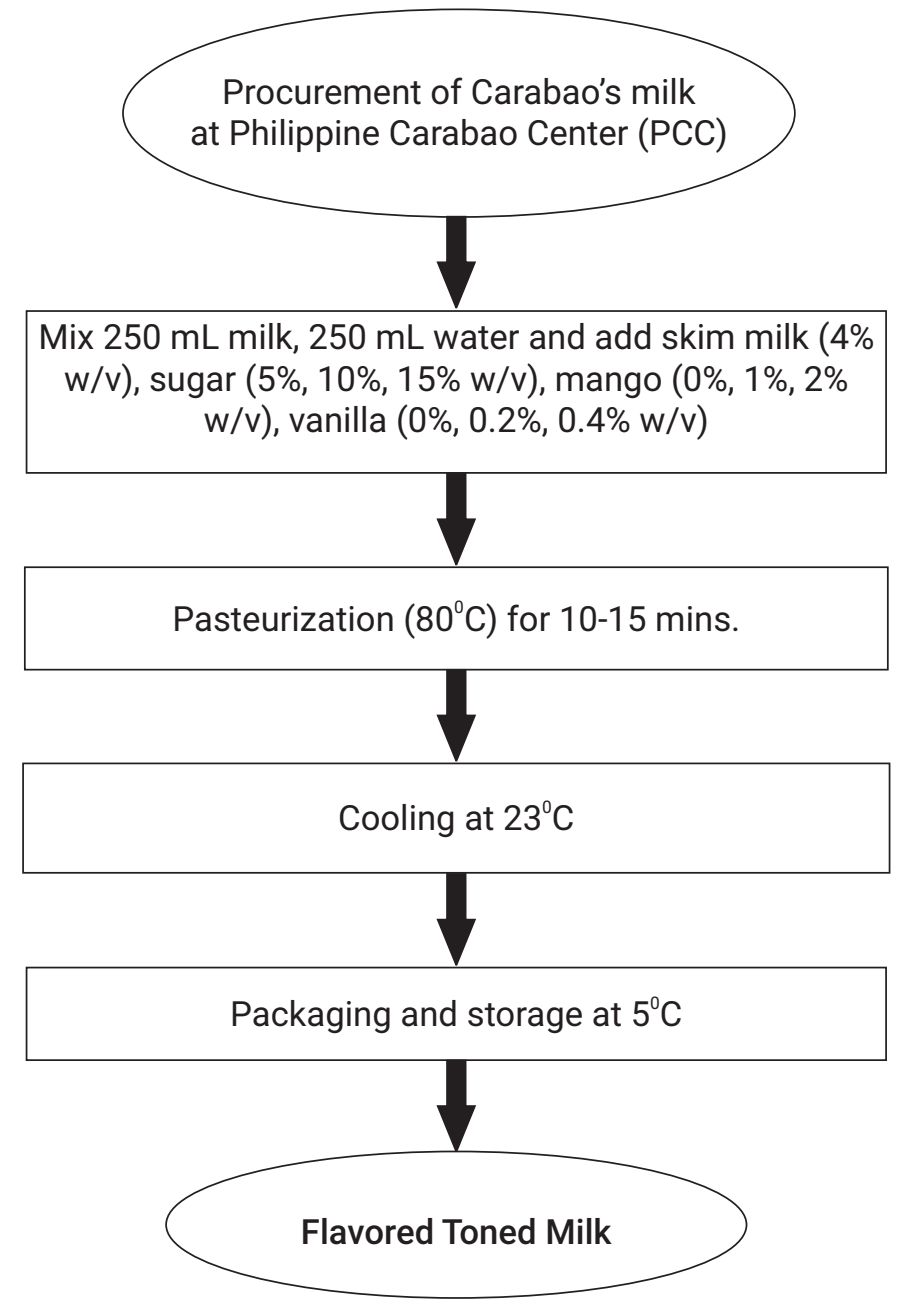

Figure 2. Process flow for flavored toned milk

\section{Cost Analysis}

The cost of processing the Flavored Toned Milk from carabao was determined for all treatments using prevailing cost of ingredients, packaging materials, and operating expenses during the conduct of the experiment. It was computed as the sum of direct material cost, labor cost, and overhead expenses. The cost was analyzed using surface regression analysis and plotted as contour plot. 


\section{Verification Study}

The optimum formulation was evaluated by thirty-two panelists who were randomly selected. The predicted and observed sensory acceptability results of the optimum treatment outside the optimum region were verified using T-test.

\section{Consumer Preference Test}

The identified optimum formulation was subjected to consumer preference test to evaluate the acceptability of the product. The commercially available fresh carabao's milk was used since it is currently the most comparable to toned milk products available in Baybay City, Leyte. The respondents were asked to choose between the two samples presented and state the reason for their choice.

$$
\begin{aligned}
\text { Percent }(\%) & =\frac{\text { No. of panelist like or dislike }}{\text { No. of total panelists }} \times 100 \\
x^{2}(\text { computed }) & =\frac{(\text { observed }- \text { expected })^{2}}{\text { expected }}
\end{aligned}
$$

\section{RESULTS AND DISCUSSION}

\section{Plackett-Burman (PB) Variable Screening}

Results of variable screening show that the addition of sugar has a positive significant effect on the mouthfeel, taste, sweetness, and general acceptability of the product. This implies that increasing the level of sugar increases the sensory acceptability of the product. Vanilla also significantly affected the aroma and taste positively, which means that the addition of vanilla enhanced the aroma and taste acceptability of the beverage. Contrary to sugar, the addition of mango significantly decreased the acceptability of the product's mouthfeel, taste, sweetness, and general acceptability.

Based on the results of the screening experiment, sugar, mango, and vanilla levels were identified as the variables used for optimization using a $3^{3}$ fractional factorial experiment, following the Central Composite Design (CCD) of Experiment with 15 treatments. 
Table 3. Summary of the effects of different variables on the sensory attributes of flavored toned milk

\begin{tabular}{lllllll}
\hline \multicolumn{1}{c}{ Variables } & Color & Aroma & Mouthfeel & \multicolumn{1}{c}{ Taste } & Sweetness & General Acc. \\
\hline Mean/Interc. & 7.4375 & 7.6473 & 7.7678 & 7.5312 & 7.383929 & 7.575893 \\
(1) Sugar level & $-0.05 \mathrm{~ns}$ & $0.169 \mathrm{~ns}$ & $0.35^{\star \star}$ & $1.098^{\star \star}$ & $1.10^{\star \star}$ & $0.93^{\star *}$ \\
(2) Skim milk level & $-0.08 \mathrm{~ns}$ & $0.169 \mathrm{~ns}$ & $-0.089 \mathrm{~ns}$ & $0.008 \mathrm{~ns}$ & $-0.0714 \mathrm{~ns}$ & $-0.0267 \mathrm{~ns}$ \\
(3) Temp. upon serv. & $-0.07 \mathrm{~ns}$ & $0.133 \mathrm{~ns}$ & $0.035 \mathrm{~ns}$ & $-0.026 \mathrm{~ns}$ & $-0.0714 \mathrm{~ns}$ & $0.0982 \mathrm{~ns}$ \\
(4) Taro level & $0.17 \mathrm{~ns}$ & $-0.008 \mathrm{~ns}$ & $0.035 \mathrm{~ns}$ & $0.098 \mathrm{~ns}$ & $-0.0178 \mathrm{~ns}$ & $0.1160 \mathrm{~ns}$ \\
(5) Cooking time & $-0.07 \mathrm{~ns}$ & $0.062 \mathrm{~ns}$ & $0.089 \mathrm{~ns}$ & $-0.008 \mathrm{~ns}$ & $0.0357 \mathrm{~ns}$ & $-0.0803 \mathrm{~ns}$ \\
(6) Vanilla level & $0.08 \mathrm{~ns}$ & $0.276^{\star}$ & $0.160 \mathrm{~ns}$ & $0.312^{\star}$ & $0.1964 \mathrm{~ns}$ & $0.1339 \mathrm{~ns}$ \\
(7) Mango level & $-0.03 \mathrm{~ns}$ & $-0.08 \mathrm{~ns}$ & $-0.267^{\star}$ & $-0.41^{\star \star}$ & $-0.41^{\star \star}$ & $-0.38^{\star *}$ \\
\hline
\end{tabular}

${ }^{\star} \mathrm{p} \leq 0.05$ = significant; ${ }^{\star \star} \mathrm{p} \leq 0.01$ = highly significant; $\mathrm{ns}=$ not significant

However, skim milk, temperature upon serving, taro level, and cooking time have no significant effect on the sensory acceptability of the product. This means that the designated two levels of each variable can only affect the sensory attributes slightly. Thus, skim milk, temperature upon serving, and cooking time were held constant, while the taro level was not included.

\section{Sensory Evaluation for Optimization Experiment}

Table 4 summarizes the parameter estimates using surface regression for the sensory attributes of flavored toned milk.

Table 4. Summary of the parameter estimates of response for the acceptability of the sensory attributes of the flavored toned milk

\begin{tabular}{|c|c|c|c|c|c|c|}
\hline \multirow[b]{2}{*}{ Parameter } & \multicolumn{6}{|c|}{ Parameter Estimates } \\
\hline & Color & Aroma & Mouthfeel & Taste & Sweetness & General Acc. \\
\hline Interc. & 7.0008 & 6.9765 & 7.1107 & 6.6749 & 6.6262 & 6.4250 \\
\hline Sugr & $0.079 \mathrm{~ns}$ & $0.0991 \mathrm{~ns}$ & $0.0574 \mathrm{~ns}$ & $0.170 \mathrm{~ns}$ & $0.26^{\star \star}$ & 0.28 ** \\
\hline Sugr^$^{\wedge}$ & $-0.003 n s$ & $-0.005 n s$ & $-0.0022 n s$ & $-0.00 \mathrm{~ns}$ & -0.01 ** & $-0.01 * \star$ \\
\hline Mang & $-0.510^{*}$ & $-0.100 n s$ & $-0.4321 n s$ & $-0.06 n s$ & $-0.4680 n s$ & $-0.84 * \star$ \\
\hline Mang $^{\wedge} 2$ & $0.134 \mathrm{~ns}$ & $0.0317 \mathrm{~ns}$ & $0.1428 \mathrm{~ns}$ & $0.153 \mathrm{~ns}$ & $0.250^{*}$ & $0.34^{\star \star}$ \\
\hline Van & $-0.495 n s$ & $1.0253 \mathrm{~ns}$ & $0.4964 \mathrm{~ns}$ & $-0.49 n s$ & $-2.6543 n s$ & $-2.832^{\star}$ \\
\hline $\operatorname{Van}^{\wedge} 2$ & $1.944 \mathrm{~ns}$ & $-0.992 n s$ & $-0.7142 n s$ & $-0.79 n s$ & $2.6984 \mathrm{~ns}$ & $5.714^{\star}$ \\
\hline Sugr*Man & $-0.000 n s$ & $0.0128 \mathrm{~ns}$ & $0.0192 \mathrm{~ns}$ & $-0.01 \mathrm{~ns}$ & $0.0064 \mathrm{~ns}$ & $0.017 n s$ \\
\hline Sugr*Van & $-0.032 n s$ & $-0.078 n s$ & $-0.0178 n s$ & $0.085 n s$ & $0.1321 \mathrm{~ns}$ & $0.075 n s$ \\
\hline Mang $\star V a$ & $0.053 \mathrm{~ns}$ & $-0.285 n s$ & $-0.3750 n s$ & $-0.07 n s$ & $-0.0892 n s$ & $-0.23 n s$ \\
\hline
\end{tabular}

${ }^{*} \mathrm{p} \leq 0.05$ = significant; ${ }^{*} \mathrm{p} \leq 0.01$ = highly significant; $\mathrm{ns}=$ not significant

Color

The color description of the flavored toned carabao's milk ranged from "white" to "dark yellow" (Table 5). The color acceptability ranged from 6.77 to 7.46 with an overall response mean of 7.11, which falls under the "Like moderately" category on the 9-point Hedonic scale. The highest color rating 
was obtained in the treatment with $15 \%$ sugar and $0.4 \%$ vanilla $\left(T_{4}\right)$. Panelists perceived the color appealing in $T_{4}$ because of its natural milky white color. The color of milk is a blend of individual effects produced by: 1) the presence of calcium caseinate or phosphate colloid particles and dispersion of fat globules which can cause scattering of light; 2) greater intake of green feed which contains carotene that imparts a yellowish color; and 3) larger fat globules and higher fat percentage which increase intensity of the yellow color. Skim milk is bluish and whey is greenish yellow in color due to the presence of riboflavin (vitamin B2) and potassium (Shurki et al 2015). On the other hand, the addition of mango intensifies the yellow color of milk resulting to a decrease in color acceptability as shown in Table 5.

Figure 3 shows the contour plots for the color acceptability of flavored toned milk. Based on the figure, increasing the amount of sugar from $12 \%$ to $15 \% \mathrm{w} / \mathrm{v}$ while decreasing the amount of mango from $0.2 \%$ to $0 \% \mathrm{w} / \mathrm{v}$ increases the color acceptability of the product. Table 4 also shows the negative significant effect of mango on the color of the product. This would indicate that the addition of mango flavoring would decrease color acceptability.

Table 5. Quality description and general mean acceptability ratings for color of flavored toned milk as affected by varying levels of sugar, mango, and vanilla

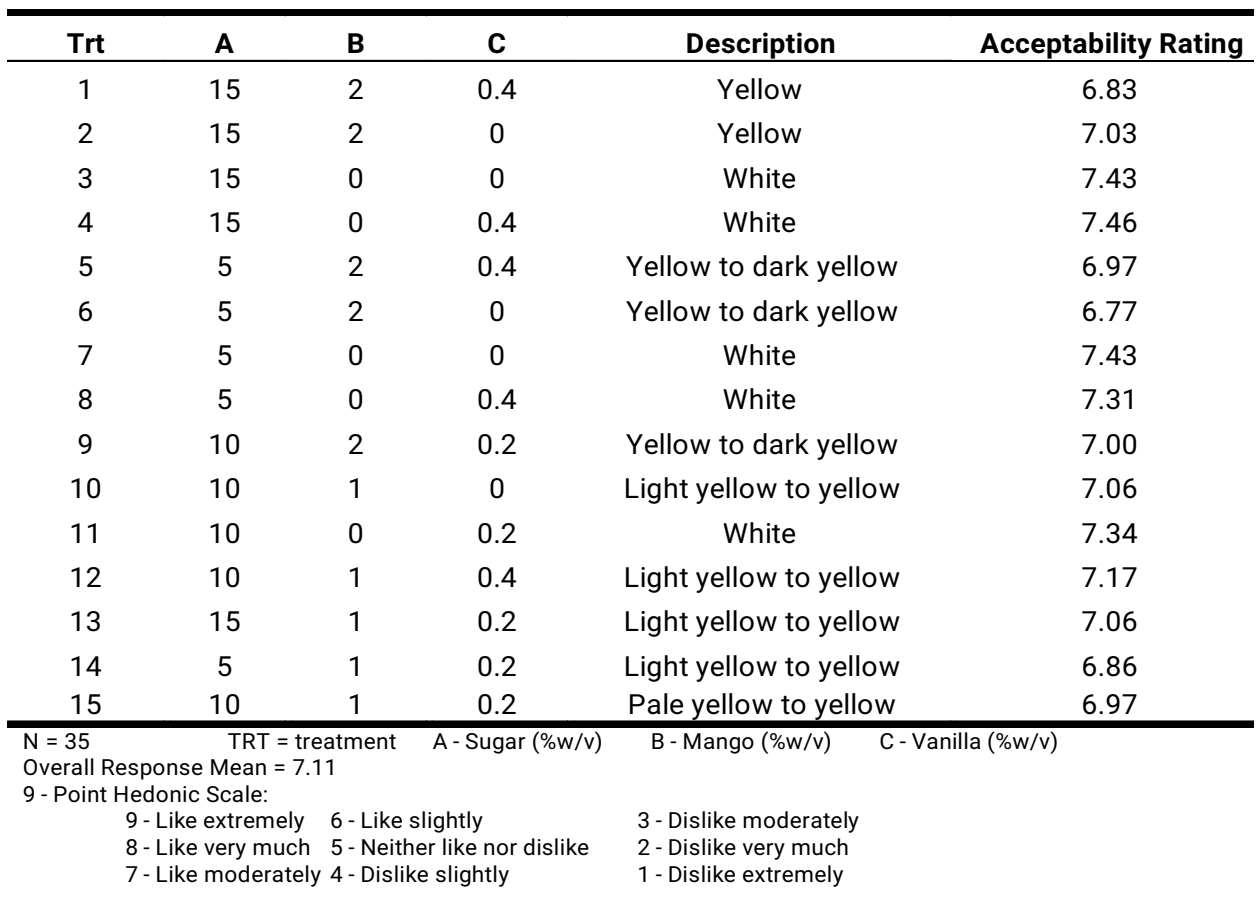




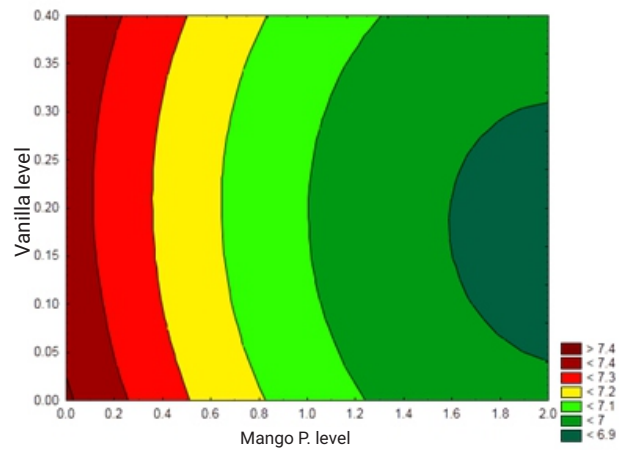

(a)

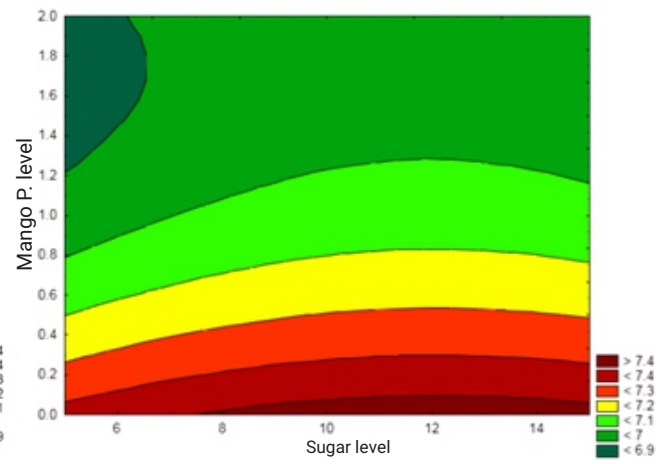

(b)

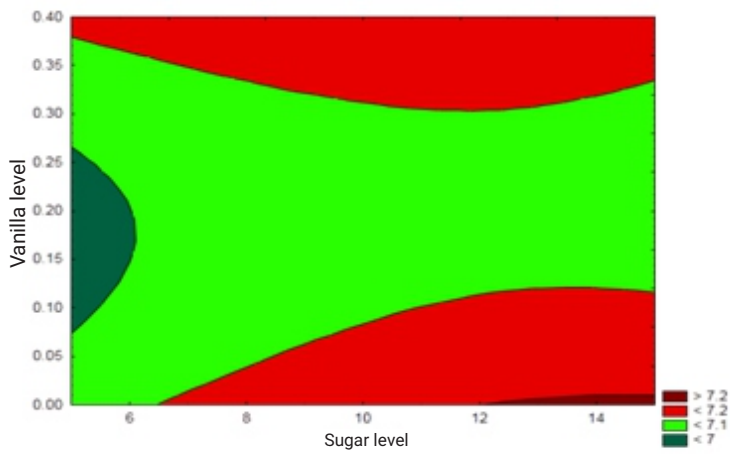

(c)

Figure 3. Contour plots for the color acceptability of flavored toned milk (a) mango vs. vanilla at constant sugar (b) sugar vs. mango at constant vanilla (c) sugar vs. vanilla at constant mango

Aroma

Some aroma active compounds, such as 1-octanol, could have a supportive impact for milk consumers which has a positive effect against essential tremor (Bushara et al 2004).

The quality description for aroma ranged from "pleasantly sweet aroma" to "more pronounced mango aroma" (Table 6). Aroma acceptability ranged from 7.09 to 7.66 with an overall response mean of 7.39 which falls under the "Like moderately" category on the 9-point Hedonic scale. The highest aroma rating was obtained in the treatment with $15 \%$ sugar, $2 \%$ mango, and $0 \%$ vanilla $\left(T_{2}\right)$. This treatment contained the highest level of sugar and mango level with the lowest level of vanilla.

Figure 4 shows the contour plots for the aroma acceptability of flavored toned milk. The graphs show that increasing the amount of mango from $1.7 \%$ to $2 \% \mathrm{w} / \mathrm{v}$ and sugar from $8.5 \%$ to $13 \% \mathrm{w} / \mathrm{v}$, increases aroma acceptability of the product. However, vanilla, mango, and sugar did not significantly affect the aroma acceptability of the product (Table 4). 
Villo, Lauzon, Amestoso F \& Amestoso N

Table 6. Quality description and mean acceptability ratings for aroma of flavored toned milk as affected by varying levels of sugar, mango, and vanilla

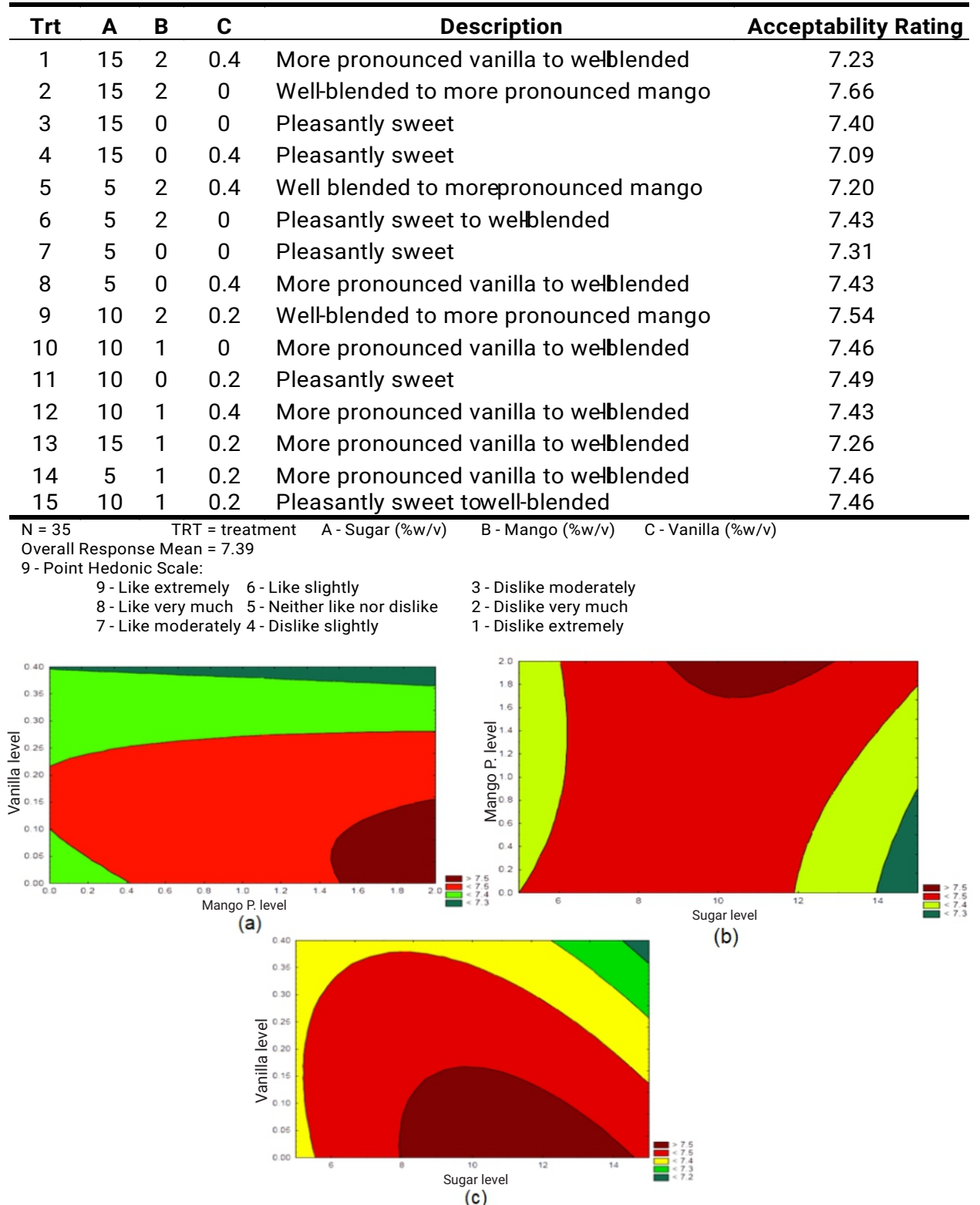

Figure 4. Contour plots for the aroma acceptability of flavored toned milk (a) mango vs. vanilla at constant sugar (b) sugar vs. mango at constant vanilla (c) sugar vs. vanilla at constant mango

\section{Mouthfeel}

Viscosity is a measure of the frictional force (resistance) of a fluid. 
Fluids resist such an applied force (or another object's motion through the fluids) with each layer's motion having different velocities. Kinematic viscosity is a measure of a fluid's resistance under the influence of the force of gravity. It is usually measured by a capillary viscometer by observing the fluid's velocity in reaching the bottom of the long tube. However, in this experiment, viscosity is measured by employing sensory panelists' perception and acceptability through sensory evaluation using the 9-point Hedonic scale. Based on the results, most of the sensory panelists described the mouthfeel from "not viscous" to "slightly viscous" (Table 7). This is because the addition of sugar increases the total solutes in the solution, thus increasing the viscosity of the product. The mean acceptability rating ranged from 7 to 7.77 with an overall response mean of 7.36 which falls under the "Like moderately" category in the 9-point Hedonic scale. The highest mouthfeel rating was obtained in treatment 2 . This treatment contained the highest level of sugar (15\%) and mango level $(2 \%)$ with the lowest level of vanilla $(0 \%)$. Panelists perceived the mouthfeel appealing in $\mathrm{T}_{2}$ because the viscosity is just right and not too thick.

Figure 5 shows the contour plots for the mouthfeel acceptability of flavored toned milk. The graphs show that increasing sugar levels increases the mouthfeel acceptability. This may be because the addition of sugar increases viscosity and may be perceived by the panelists as the wholeness of the toned milk.

Table 7. Quality description and mean acceptability ratings for mouthfeel of flavored toned milk as affected by varying levels of sugar, mango, and vanilla

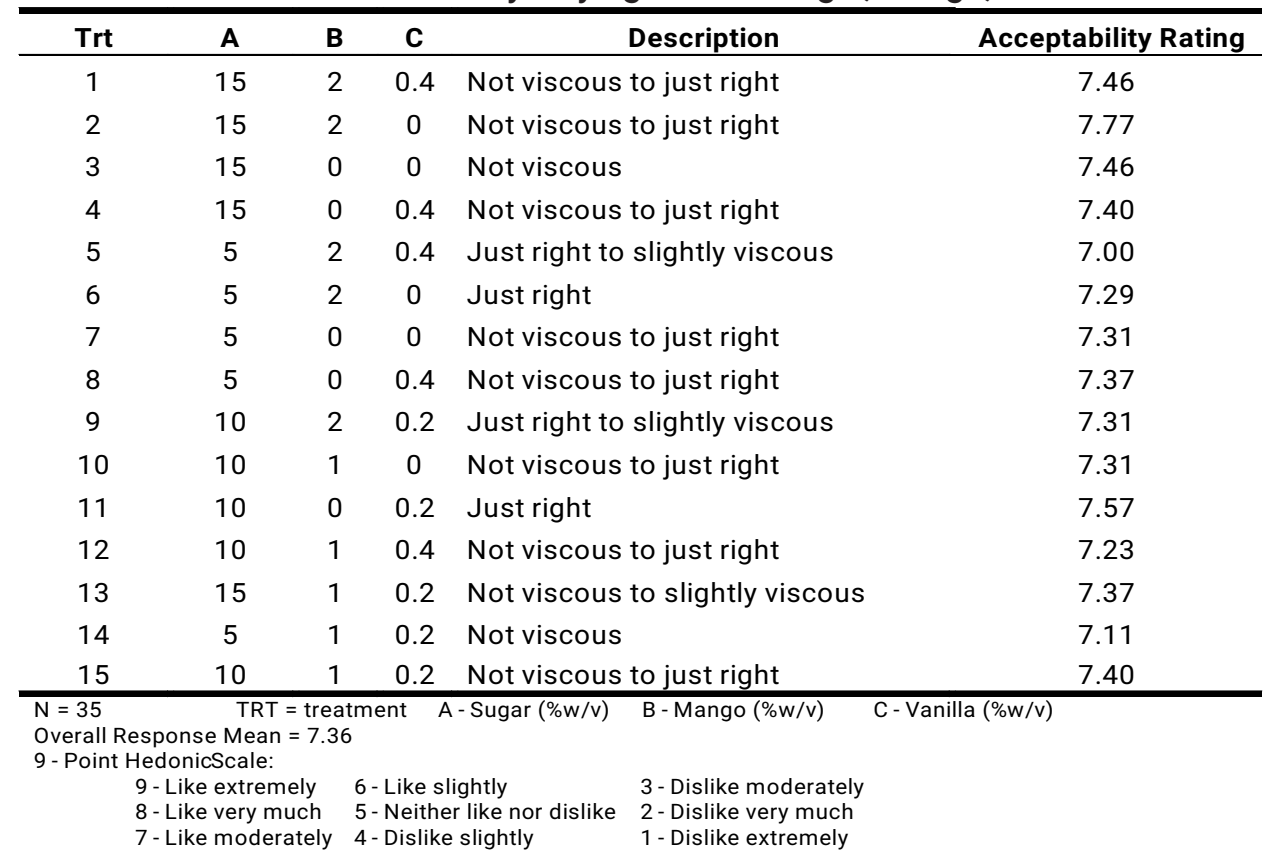




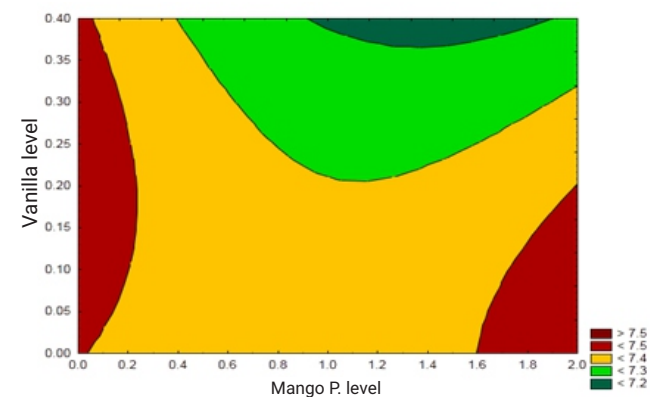

(a)

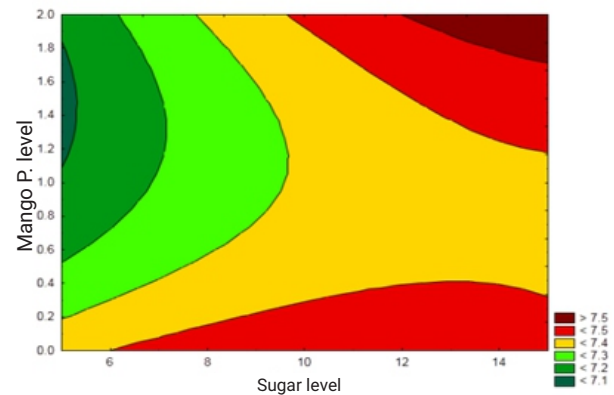

(b)

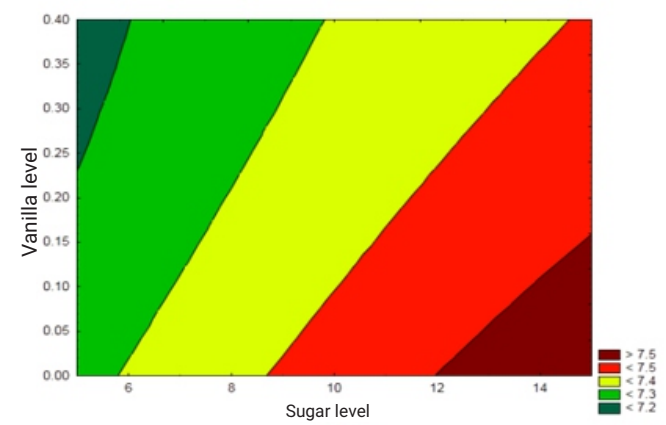

(c)

Figure 5. Contour plots for the mouthfeel acceptability of flavored toned milk (a) mango vs. vanilla at constant sugar (b) sugar vs. mango at constant vanilla (c) sugar vs. vanilla at constant mango

\section{Taste}

Good quality milk should have a pleasantly sweet and clean flavor with no distinct aftertaste. Because of the perishability of milk and the nature of milk production and handling procedures, the development of offflavors/odors is not uncommon.

Most of the sensory panelists perceived the taste of flavored toned milk from "More pronounced mango taste" to "Very strong milky taste" (Table 8). Taste acceptability perceived by panelists ranged from 7.2 to 7.74 with an overall response mean of 7.41 which falls under the "Like moderately" category on the 9-point Hedonic scale. The highest taste rating was obtained in treatment 9 . This treatment contains the highest level of mango $(2 \%)$ and mid-levels of vanilla (0.2\%) and sugar (10\%). The graphs (Figure 6) show that $0.2 \%$ vanilla, $2 \%$ mango, and $10 \%$ sugar were more acceptable among consumers. However, taste was not significantly affected by the variables (Table 4). 


\section{Optimization of Flavored Toned Milk from Carabao}

Table 8. Quality description and mean acceptability ratings for taste of flavored toned milk as affected by varying levels of sugar, mango, and vanilla

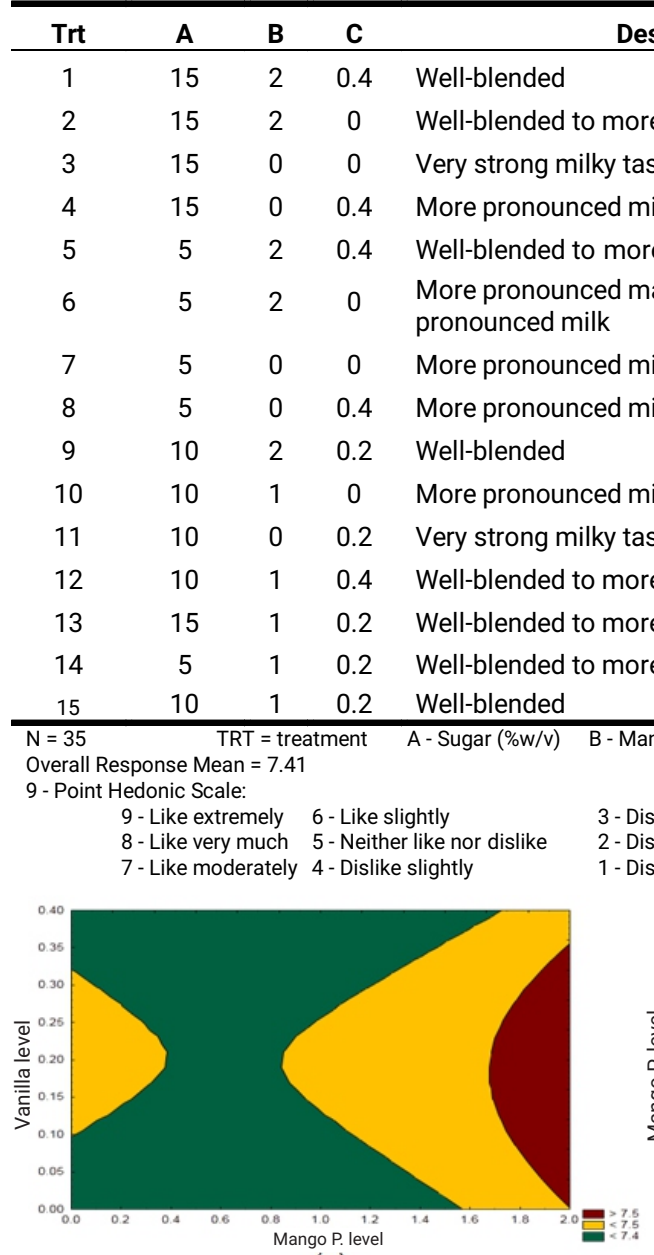

(a)
Description

Acceptability Rating

7.43

7.26

7.37

7.40

7.34

7.71

7.31

7.20

7.74

7.31

7.49

7.54

7.26

7.23

7.51

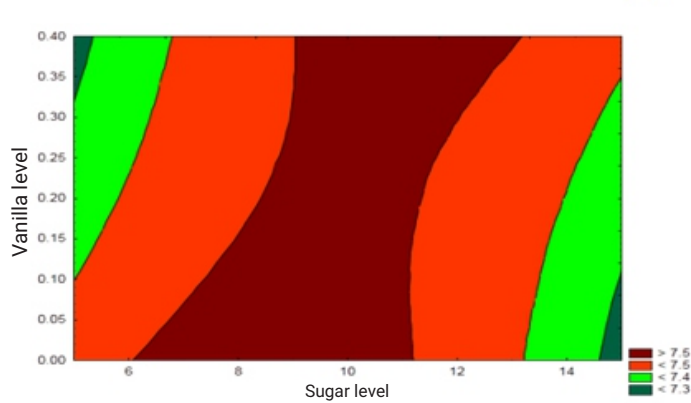

(c)

Figure 6.Contour plots for the taste acceptability of flavored toned milk (a) mango vs. vanilla at constant sugar (b) sugar vs. mango at constant vanilla (c) sugar vs. vanilla at constant mango 
Based on the results, the sweetness description perceived by the sensory panelists ranged from "Slightly sweet" to "Very sweet" (Table 9). The sweetness acceptability ranged from 7.06 to 7.8 with an overall response mean of 7.32 which falls under the "Like moderately" on the 9point Hedonic scale. The highest sweetness rating was obtained in the treatment with $10 \%$ sugar, $2 \%$ mango, and $0.2 \%$ vanilla $\left(T_{9}\right)$, while the treatment with $15 \%$ sugar, $0 \%$ mango, and vanilla $\left(\mathrm{T}_{3}\right)$ and the treatment with $5 \%$ sugar, $1 \%$ mango, and $0.2 \%$ vanilla $\left(T_{14}\right)$ got the lowest ratings for sweetness. Panelists perceived the sweetness appealing in $T_{9}$ because the level of sugar was just right, while $T_{14}$, having the least concentration of sugar, was perceived as slightly sweet and $T_{3}$, having the highest concentration of sugar, was just too sweet. Both treatments resulted to lower mean acceptability ratings. However, their mean acceptability ratings did not significantly differ from each other.

Figure 7 shows the contour plots for the sweetness acceptability of flavored toned milk. Results indicated that mid-levels of sugar is more acceptable to consumers. Table 4 also presents that the addition of sugar had a positive effect on the sweetness attribute.

Table 9. Quality description and mean acceptability ratings for sweetness of flavored toned milk as affected by varying levels of sugar, mango, and vanilla

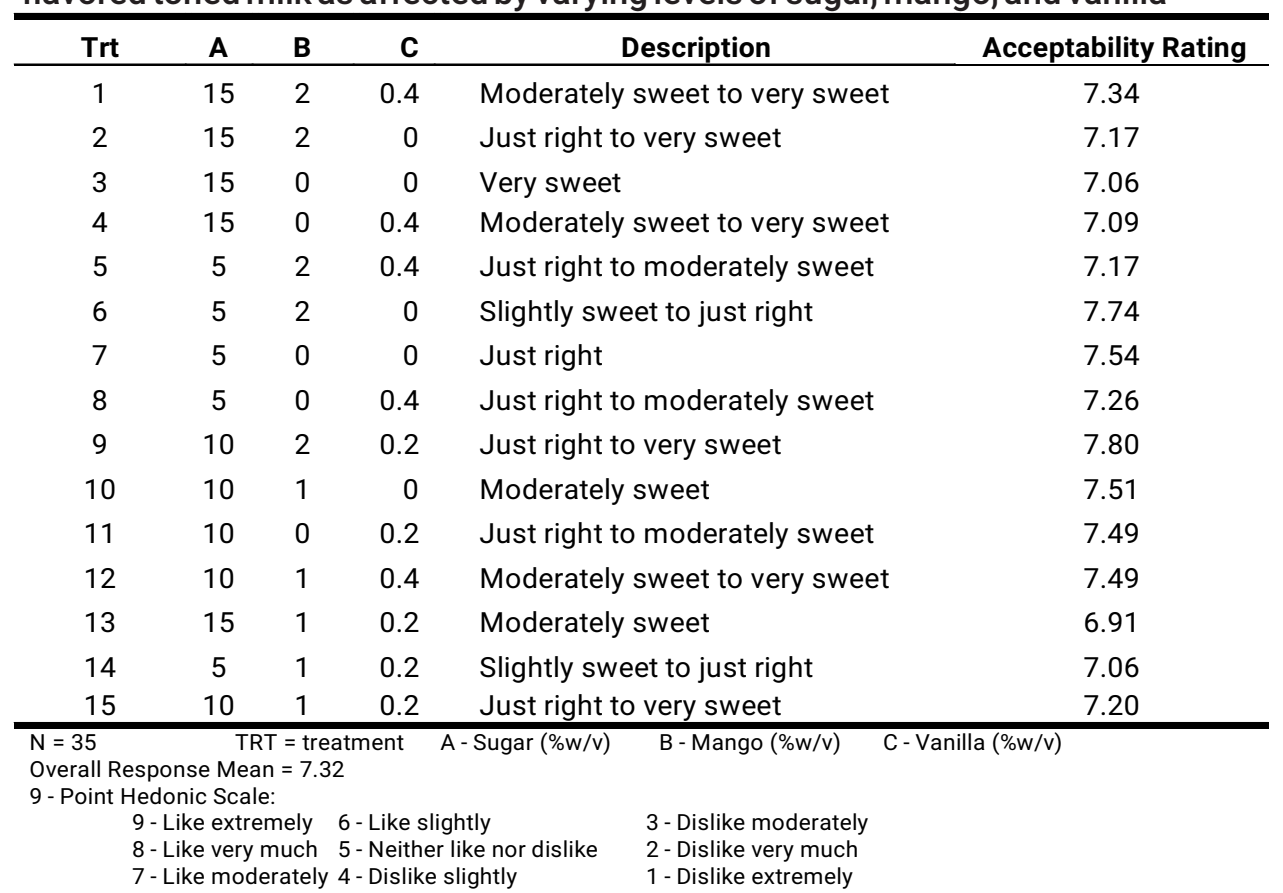




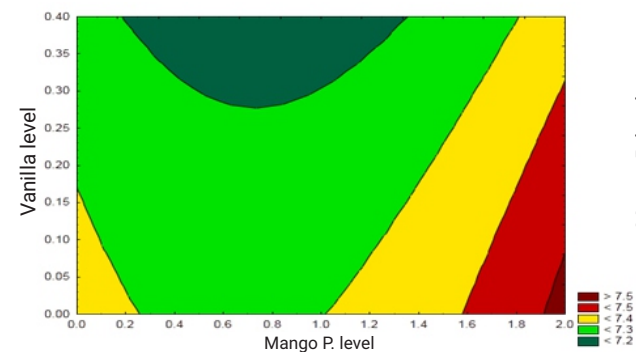

(a)

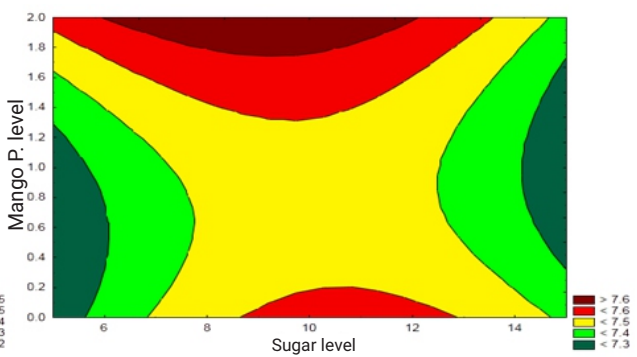

(b)

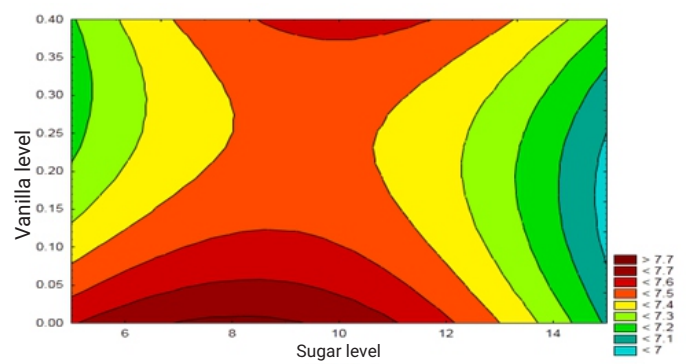

(c)

Figure 7.Contour plots for the sweetness acceptability of flavored toned milk (a) mango vs. vanilla at constant sugar (b) sugar vs. mango at constant vanilla (c) sugar vs. vanilla at constant mango

\section{General Acceptability}

Color, aroma, mouthfeel, taste, sweetness, and general acceptability were all considered in evaluating the overall acceptability of flavored toned milk. Mean acceptability ratings for general acceptability is presented in Table 10. The general acceptability rating ranged from 7 to 7.51 with an overall response mean of 7.24 which falls under the "Like moderately" category on the 9-point Hedonic scale.

The treatment with the lowest mean acceptability rating is the treatment with $5 \%$ sugar, $2 \%$ mango, and $0.4 \%$ vanilla $\left(T_{5}\right)$. The low level of sugar resulted in the lack of sweetness of the beverage. It also got the lowest mean acceptability rating for mouthfeel. Panelists preferred the right sweetness and mouthfeel of treatment 12. Apparently, treatment 2 had the highest mean in aroma and mouthfeel acceptability rating while treatment 9 had the highest mean acceptability rating in terms of taste and sweetness.

Figure 8 shows the contour plots for the mean general acceptability of flavored toned milk. It shows that mid-levels of sugar is more acceptable to the panelists. Regression analysis statistically shows that sugar, mango, and vanilla level significantly affected the overall quality of flavored toned milk (Table 4). 
Villo, Lauzon, Amestoso F \& Amestoso N

Table 10. Mean acceptability rating for general acceptability of flavored toned milk as affected by varying levels of sugar, mango, and vanilla

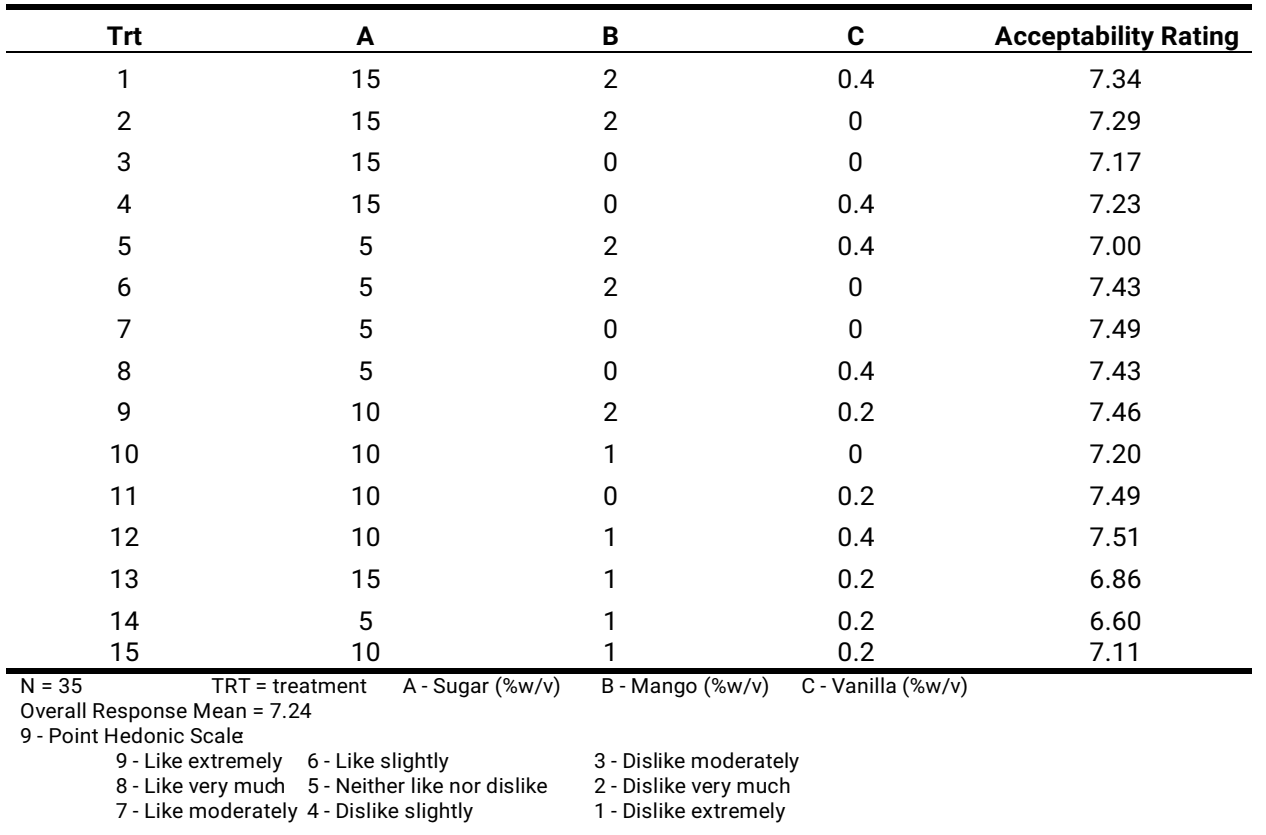

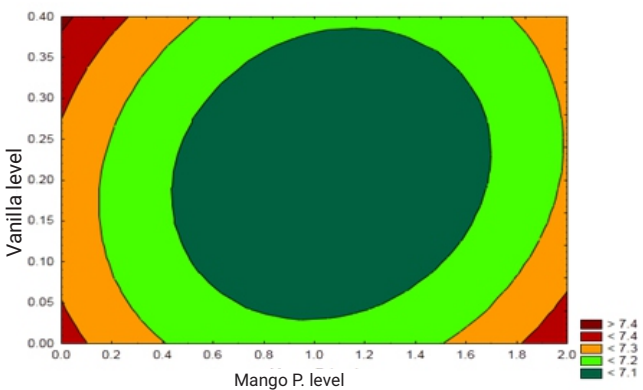

(a)

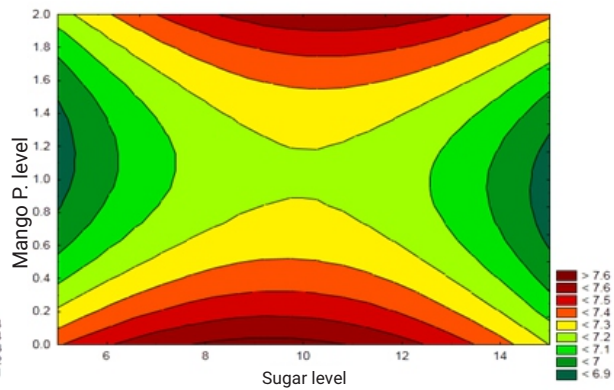

(b)

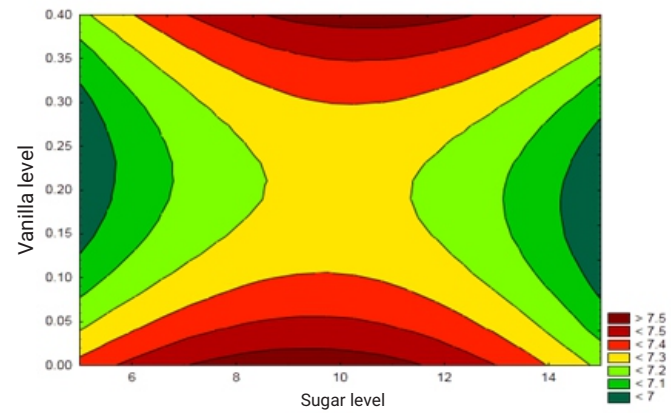

(c)

Figure 8. Contour plots for the general acceptability of flavored toned milk (a) mango vs. vanilla at constant sugar (b) sugar vs. mango at constant vanilla (c) sugar vs. vanilla at constant mango 


\section{Optimization of Flavored Toned Milk from Carabao}

\section{Cost Analysis}

The cost of producing flavored toned milk consisted of the cost of raw materials, labor, and overhead. The cost of producing 1 liter of flavored toned milk was affected by varying levels of sugar, mango, and vanilla as shown in Table 11. Treatment 7, with low levels of sugar, mango, and vanilla, obtained the lowest cost of Php 71.37 while treatment 1, with the highest levels among all variables, obtained the highest cost of Php 86.31. Figure 9 shows the contour plots for the cost analysis of flavored toned milk. Based on the figures, increasing the levels of any of the three ingredient variables: sugar, mango, and vanilla, will also increase cost.

Table 11. Production cost of 1 liter flavored toned milk as affected by varying levels of sugar, mango, and vanilla

\begin{tabular}{ccccc}
\hline Trt & A & B & C & Cost Per Liter (P) \\
\hline 1 & 15 & 2 & 0.4 & 86.31 \\
2 & 15 & 2 & 0 & 84.31 \\
3 & 15 & 0 & 0 & 76.07 \\
4 & 15 & 0 & 0.4 & 78.07 \\
5 & 5 & 2 & 0.4 & 81.61 \\
6 & 5 & 2 & 0 & 79.61 \\
7 & 5 & 0 & 0 & 71.37 \\
8 & 5 & 0 & 0.4 & 73.37 \\
9 & 10 & 2 & 0.2 & 82.96 \\
10 & 10 & 1 & 0 & 77.84 \\
11 & 10 & 0 & 0.2 & 74.72 \\
12 & 10 & 1 & 0.4 & 79.84 \\
13 & 15 & 1 & 0.2 & 81.19 \\
14 & 5 & 1 & 0.2 & 76.49 \\
15 & 10 & 1 & 0.2 & 78.84 \\
Optimum & 13.6 & 0 & 0.12 & 76.00 \\
\hline TRT = treatment & A-Sugar (\%w/v) B-Mango (\%w/v) & C-Vanilla (\%w/v) & &
\end{tabular}




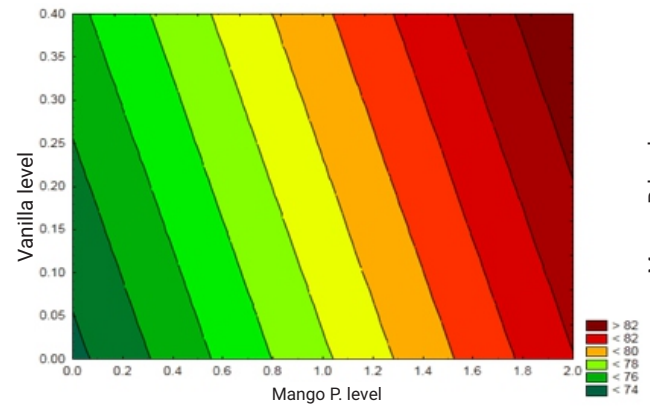

(a)

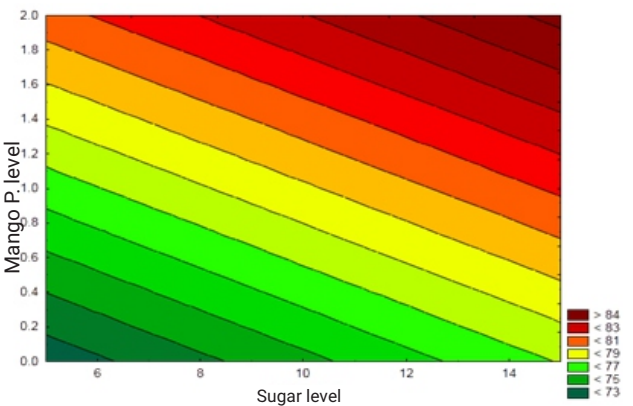

(b)

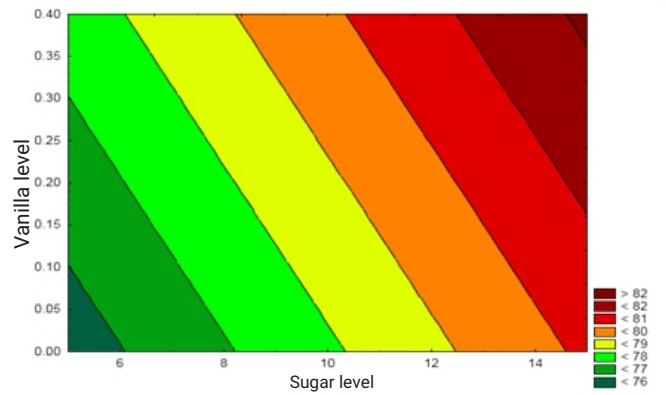

(c)

Figure 9. Contour plots for the cost analysis of flavored toned milk (a) mango vs. vanilla at constant sugar (b) sugar vs. mango at constant vanilla (c) sugar vs. vanilla at constant mango

\section{Optimum Region in the Experiment}

The location of the optimum region was determined by superimposing the contour plots of all the sensory attributes being assessed at acceptability $\geq 7.1$. Figure 10 shows the superimposed contour plots of flavored toned milk at constant levels of sugar, mango, and vanilla. At constant $10 \% \mathrm{w} / \mathrm{v}$ sugar, the shaded region was found between 0 to $0.8 \% \mathrm{w} / \mathrm{v}$ mango and 0 to $0.4 \% \mathrm{w} / \mathrm{v}$ vanilla (Figure 10a). Only color acceptability limits the region. At constant $0.2 \% \mathrm{w} / \mathrm{v}$ vanilla level, low levels of mango at 0 to $0.8 \% \mathrm{w} / \mathrm{v}$ and sugar ranging from 0 to $14.75 \% \mathrm{w} / \mathrm{v}$ filled the optimum region (Figure 10b). The figure also shows that color, sweetness, and general acceptability limits the region. At constant $1 \% \mathrm{w} / \mathrm{v}$ mango level, the shaded region was found between 0 to $0.12 \% \mathrm{w} / \mathrm{v}$ vanilla and 6.5 to $14.8 \% \mathrm{w} / \mathrm{v}$ sugar (Figure 10c). The region was limited by color, sweetness, and general acceptability. The optimum formulation identified was at sugar level of $13.6 \% \mathrm{w} / \mathrm{v}$, vanilla level of $0.12 \% \mathrm{w} / \mathrm{v}$, and mango level at $0 \% \mathrm{w} / \mathrm{v}$. 


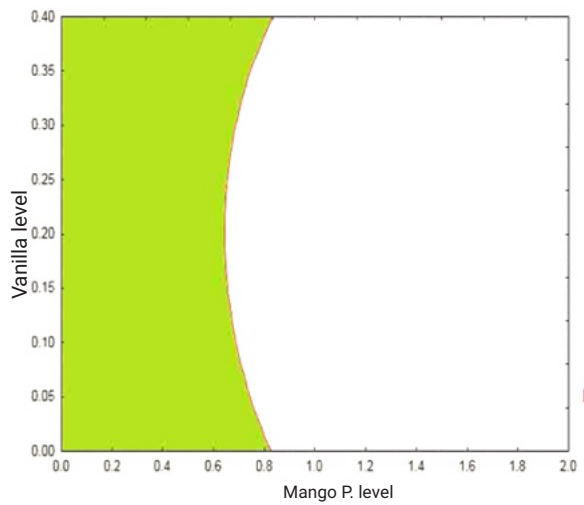

(a)

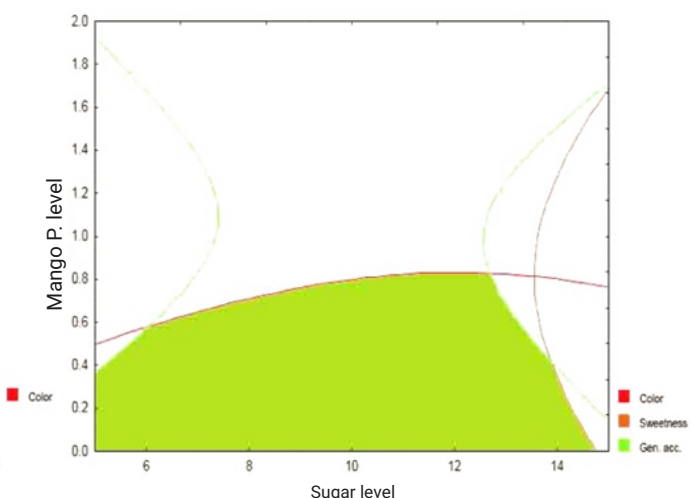

(b)

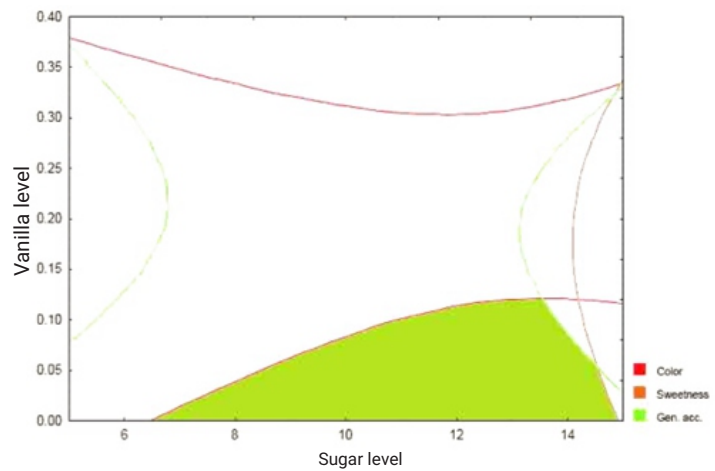

(c)

Figure 10. Optimum region for flavored toned milk at acceptability $\geq 7.1$ (a) mango vs. vanilla at constant sugar (b) sugar vs. mango at constant vanilla (c) sugar vs. vanilla at constant mango

\section{Verification}

Table 12 shows the T-test results for comparing the predicted and actual observed sensory acceptability of the optimum treatment. Results revealed that among the responses, only the values of the actual and predicted aroma acceptability of the product were not significantly different. This implies that the proposed model equation is appropriate only for predicting the aroma acceptability of the product. The observed acceptability had a higher rating than the predicted value indicating that the panelists may have improved their evaluation with less confusion when there were only two samples presented. The model equations used to obtain the predicted values are presented in Table 13. Table 14 also shows that the coefficient of determination $\left(R^{2}\right)$ only ranged from 0.00 to 0.04 y which indicates that the chances of determining the predicted values are too low because it is difficult to obtain higher $R^{2}$ values when panelists were not trained. 
Table 12. T-test results of verification test for comparing the predicted and observed sensory acceptability of the optimum treatment

\begin{tabular}{|c|c|c|c|c|c|c|}
\hline & Color & Aroma & Mouthfeel & Taste & Sweetness & General Acc. \\
\hline Actual & $8.23 \pm 0.73$ & $7.67 \pm 1.09$ & $7.93 \pm 0.87$ & $7.97 \pm 0.76$ & $7.70 \pm 0.99$ & $7.93 \pm 0.98$ \\
\hline Predicted & 7.30 & 7.39 & 7.47 & 7.43 & 7.26 & 7.25 \\
\hline $\mathrm{t}$-value & 8.46 & 1.77 & 3.34 & 4.39 & 2.80 & 4.30 \\
\hline p-value & 0.0000 & 0.0871 & 0.0023 & 0.0001 & 0.0089 & 0.0002 \\
\hline Remarks & ** & ns & $\star \star$ & $\star \star$ & $\star \star$ & $\star *$ \\
\hline
\end{tabular}

Table 13. Model equations used in predicting optimum treatment acceptability

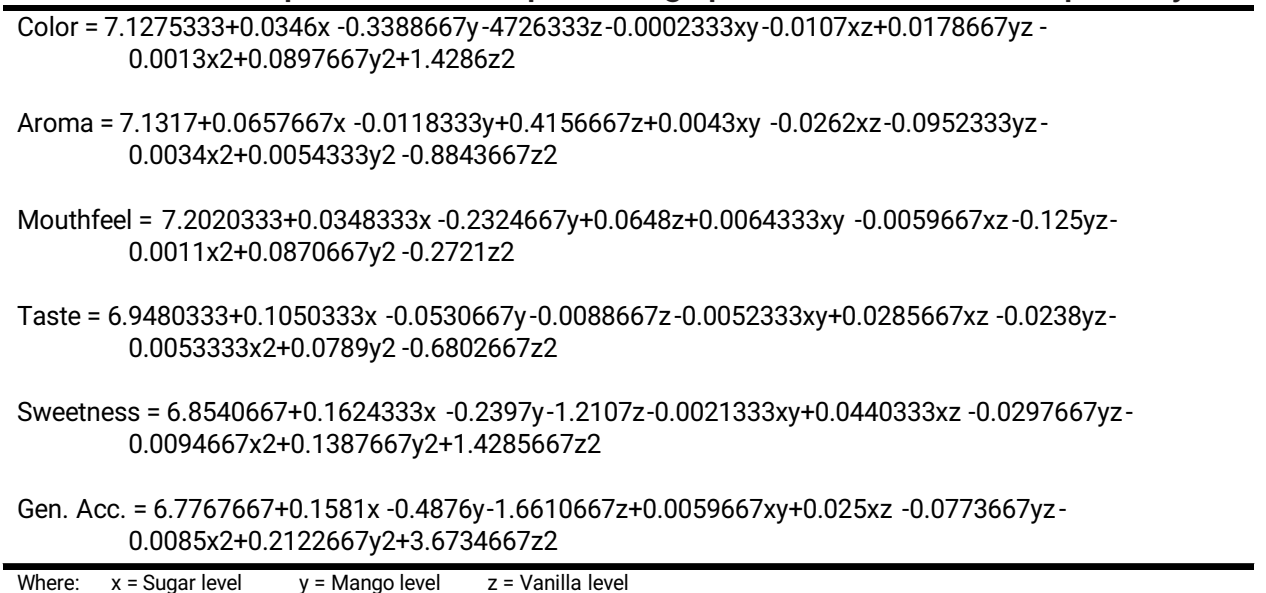

\section{Consumer Preference Test}

The optimum formulation of flavored toned milk and the commercial chocolate milk were subjected to consumer evaluation to assess the acceptability of the beverage and to evaluate the preference of consumers between the newly developed milk and the existing milk product in the local market. This was also done to check the market potential of the optimum formulation of the flavored toned milk product. A total of 100 respondents composed of 72 young adults (20 years and below, high school to college students) and 28 adults (above 20 years, VSU faculty and staff) participated in the evaluation (Figure 11). Figure 12 shows the total number of respondents: 33 were males and 67 were females.

Based on the results, $88 \%$ of the respondents liked the optimum formulation and $90 \%$ also liked the existing commercial product (Figure 13). In terms of preference, the optimum formulation was chosen by $45 \%$ of the respondents while the existing commercial product was preferred by $55 \%$. This implies that the existing commercial product had higher preference rating against the formulated flavored toned milk. The main reason is that most of the consumers have been drinking the chocolate milk that has been 
Optimization of Flavored Toned Milk from Carabao

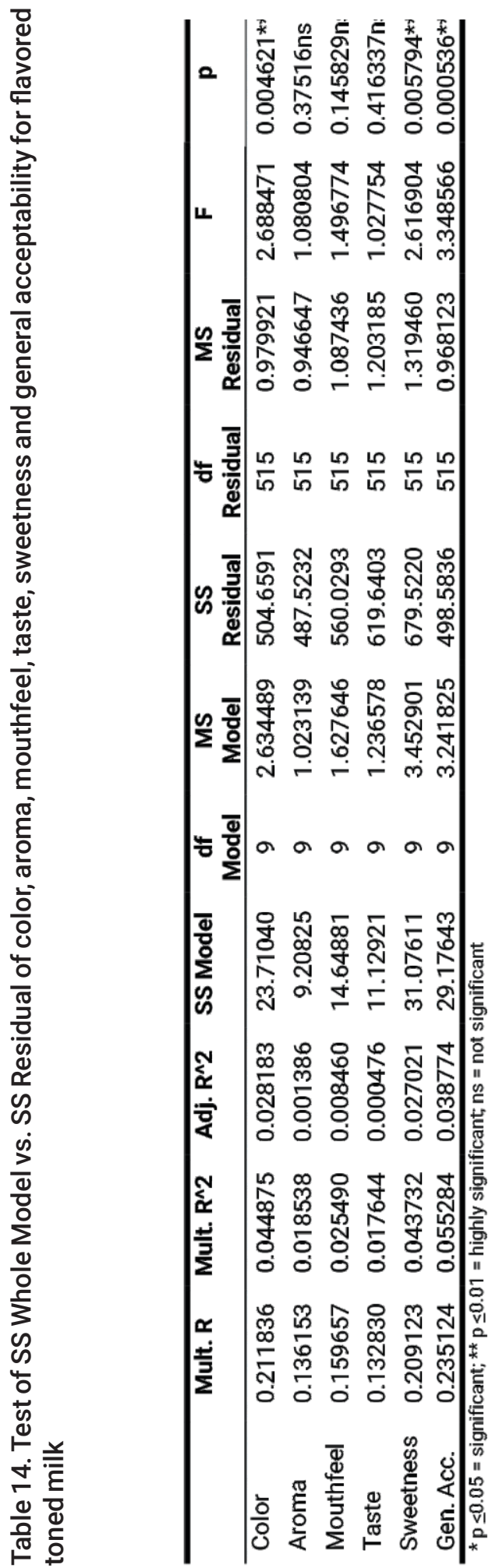


in the market for years. In general, chocolate is the most loved flavor of the respondents, especially children.

However, the Chi-square test results (Table 15) show that even though the existing commercial product is slightly more preferred by the consumers, there was no significant difference among the two. This means that the level of acceptability of both products is almost the same, indicating that the optimum formulation can compete with the existing commercial product in terms of sensory acceptability.

It is also important to consider that the cost of production was not included in the consumer test. A liter of commercial chocolate would cost Php 80 , while the optimum, which used a sugar level of $13.6 \% \mathrm{w} / \mathrm{v}$, vanilla level of $0.12 \% \mathrm{w} / \mathrm{v}$, and mango level at $0 \% \mathrm{w} / \mathrm{v}$, in the consumer preference test would only cost Php 76 per liter. Thus, if cost were included in the test, the consumers might prefer the optimum formulation.

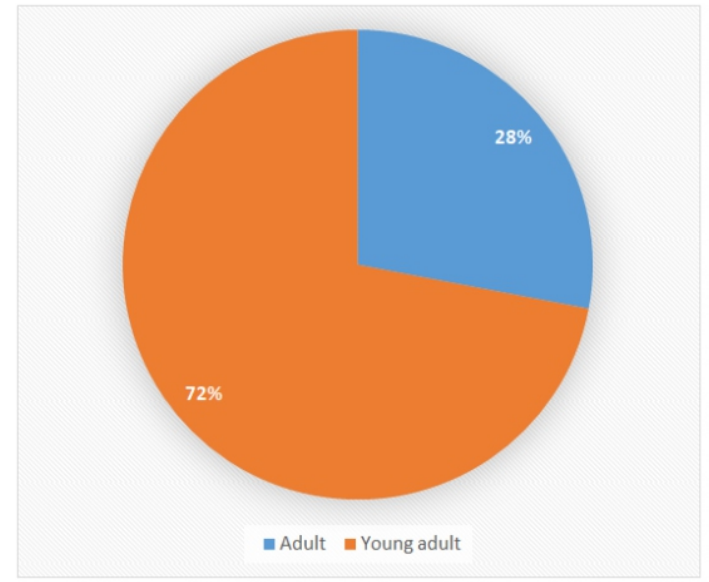

Figure 11. Age profile of the consumers

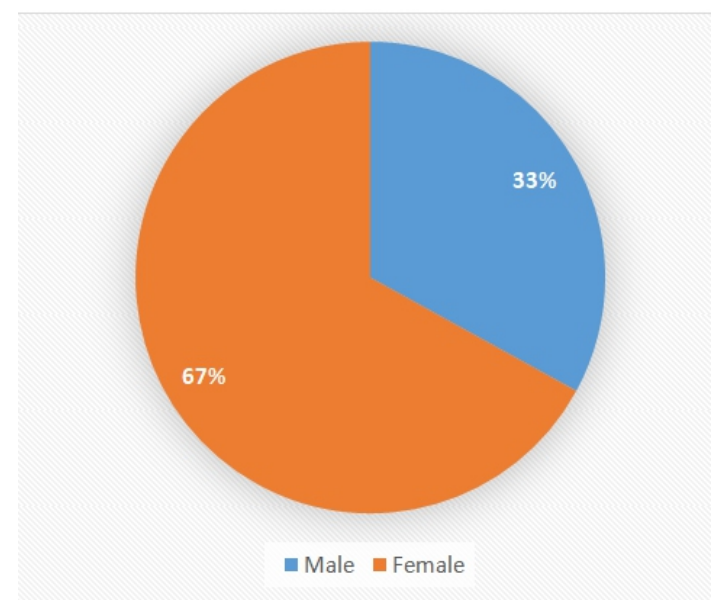

Figure 12. Sex profile of consumers 


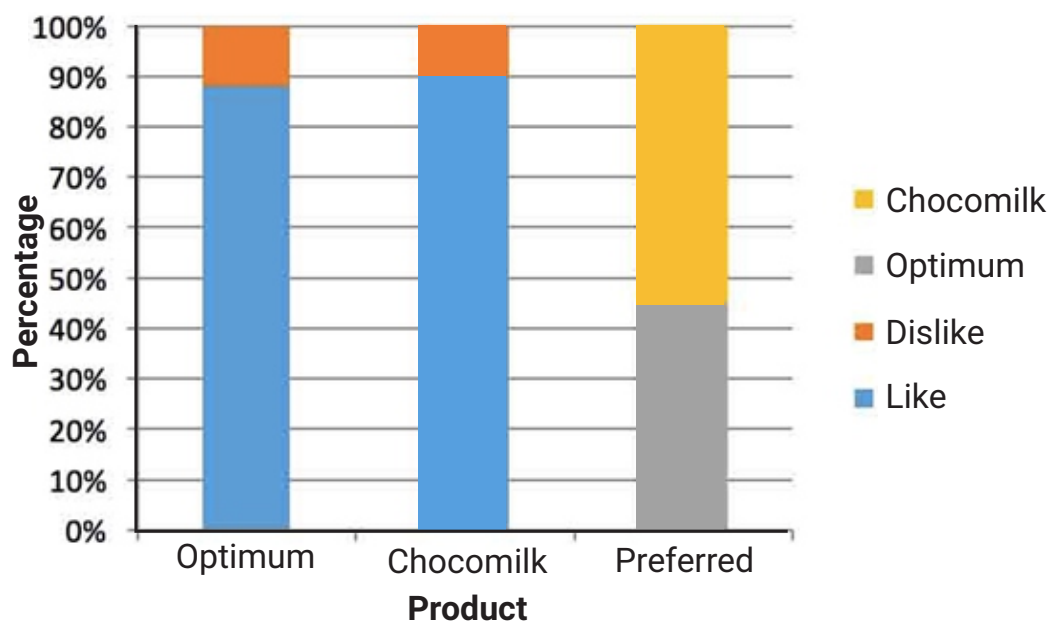

Figure 13. Graphical representation of the likeness and preference between optimum formulation of flavored toned milk and commercial product among respondents

Table 15. Chi-square test results in consumer preference between the optimum formulation of flavored toned milk and the commercial product

\begin{tabular}{cccc}
\hline Optimum & Chocomilk & Chi-Value & P-Value \\
\hline 45 & 55 & 0.317 & $0.573 \mathrm{~ns}$ \\
\hline
\end{tabular}

ns = not significant

\section{CONCLUSION AND RECOMMENDATIONS}

Several factors were included in the Plackett-Burman screening, namely: sugar, skim milk, temperature upon serving, taro, cooking time, vanilla, and mango. After screening, sugar, vanilla extract, and mango were chosen for the optimization experiment using Central Composite Design. Contour plots of all the sensory acceptability variables were superimposed to determine the location of the optimum formulation. The optimum region signifies the most acceptable and most promising formulation in the processing of flavored toned milk considering the sensory attributes. In order to confirm that the established optimum formulation is the most acceptable level combination of sugar, vanilla, and mango, a verification test was conducted. The predicted values of the sensory attributes were computed using the model equation and t-test (single sample) analysis was used to determine its difference with the observed value during the experiment.

The result of regression analysis shows the independent variables have significant effects on color, sweetness, and general acceptability of flavored toned milk. The optimum formulation identified was at sugar level of $13.6 \%$ $\mathrm{w} / \mathrm{v}$, vanilla level of $0.12 \% \mathrm{w} / \mathrm{v}$, and mango level of $0 \% \mathrm{w} / \mathrm{v}$. Observed 
acceptability had a higher rating than the predicted value indicating that the panelists may have improved their evaluation with less confusion when there were only two samples presented.

It is recommended that other flavors be used to add more variations in carabao's milk. The use of a trained panel for sensory evaluation to minimize extreme effects is recommended. The use of alternative sources of ingredients is also advised to minimize cost. Toned milk can be double toned to further lessen milk fat content and decrease cost. A complete proximate analysis of the final product must be conducted. It is also recommended to standardize the milk fat content of the pasteurized milk before the toning process to ensure consistency in the production and quality.

\section{REFERENCES}

Bushara KO, Goldstein SR, Grimes Jr GJ, Burstein AH, \& Hallett M. 2004.Pilot trial of 1-octanol in essential tremor. Neurology. 62(1): 122-124. ISSN 0028-3878.

Cochran WG and COX. 1957. Experimental Designs Second Edition. New York. 613 pp.

Food and Agriculture Organization (FAO) of the United Nations. 2017. Milk and dairy products in human nutrition. Retrieved from http://www.fao.org/docrep/018/i3396e/i3396e.pdf on April 24, 2017.

KreißI A. 2009. Malnutrition in the Philippines - perhaps a double burden?Journal für Ernährungsmedizin. Retrieved from http://www.kup.at/kup/pdf/8113.pdf, 2009 on April 21, 2017.

Shurki $M$ and Halil K. 2015. The factors importance to economization produced cheese mozzarella from cow's milk. Research Inventy: International Journal Of Engineering and Science 5(6):29-35. 